\title{
Botulinum Neurotoxin: Unique Folding of Enzyme Domain of the Most Poisonous Poison
}

\author{
Supporting Material \\ Raj Kumar ${ }^{1}$, Roshan V. Kukreja ${ }^{1}$, Li Li ${ }^{1}$, Artem Zhmurov ${ }^{3}$, Olga Kononova ${ }^{3}$, \\ Shuowei Cai ${ }^{1}$, Syed A. Ahmed ${ }^{2}$, Valeri Barsegov ${ }^{3 *}$, and Bal Ram Singh ${ }^{1 *}$

\begin{abstract}
${ }^{1}$ Botulinum Research Center and Department of Chemistry and Biochemistry, University of Massachusetts Dartmouth MA 02747; ${ }^{2}$ US Army Medical Research Institute of Infectious Diseases, Ft. Detrick, MD 21702; ${ }^{3}$ Department of Chemistry, University of Massachusetts, Lowell, MA 01854.
\end{abstract}

To whom correspondence should be addressed:

bsingh@umassd.edu and Valeri_Barsegov@uml.edu 


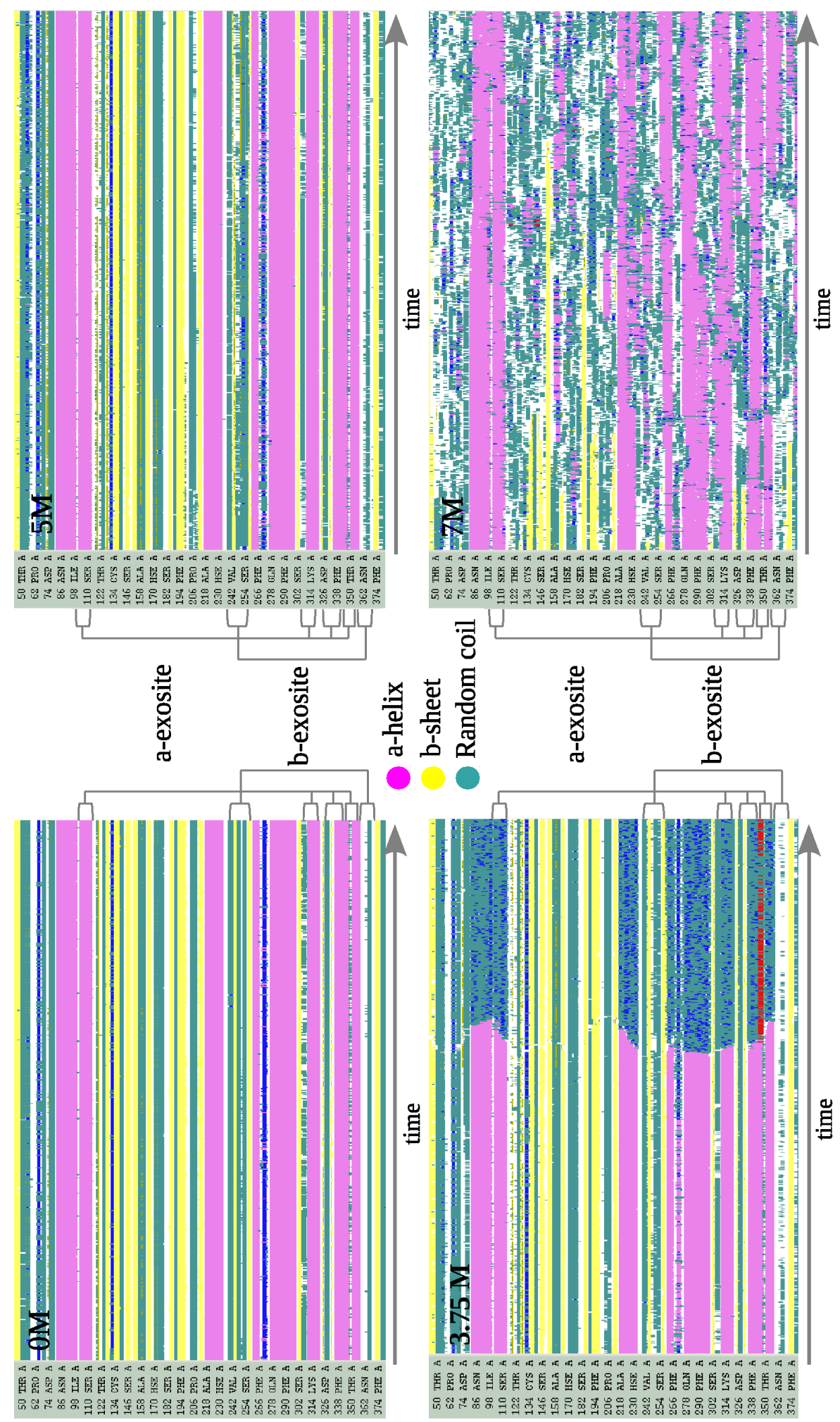

Figure S1. Secondary structure dynamics of the BoNT/A in urea solution from MD simulations at $25{ }^{\circ} \mathrm{C}$. Shown are the secondary structure propensities of various residues as a function of time. Color denotation for $\alpha$-helices, $\beta$-sheets, and random coil is presented in the graph (turns, $3_{10}$-helices, and $\pi$-helices are shown in blue, red and gray color, respectively). 

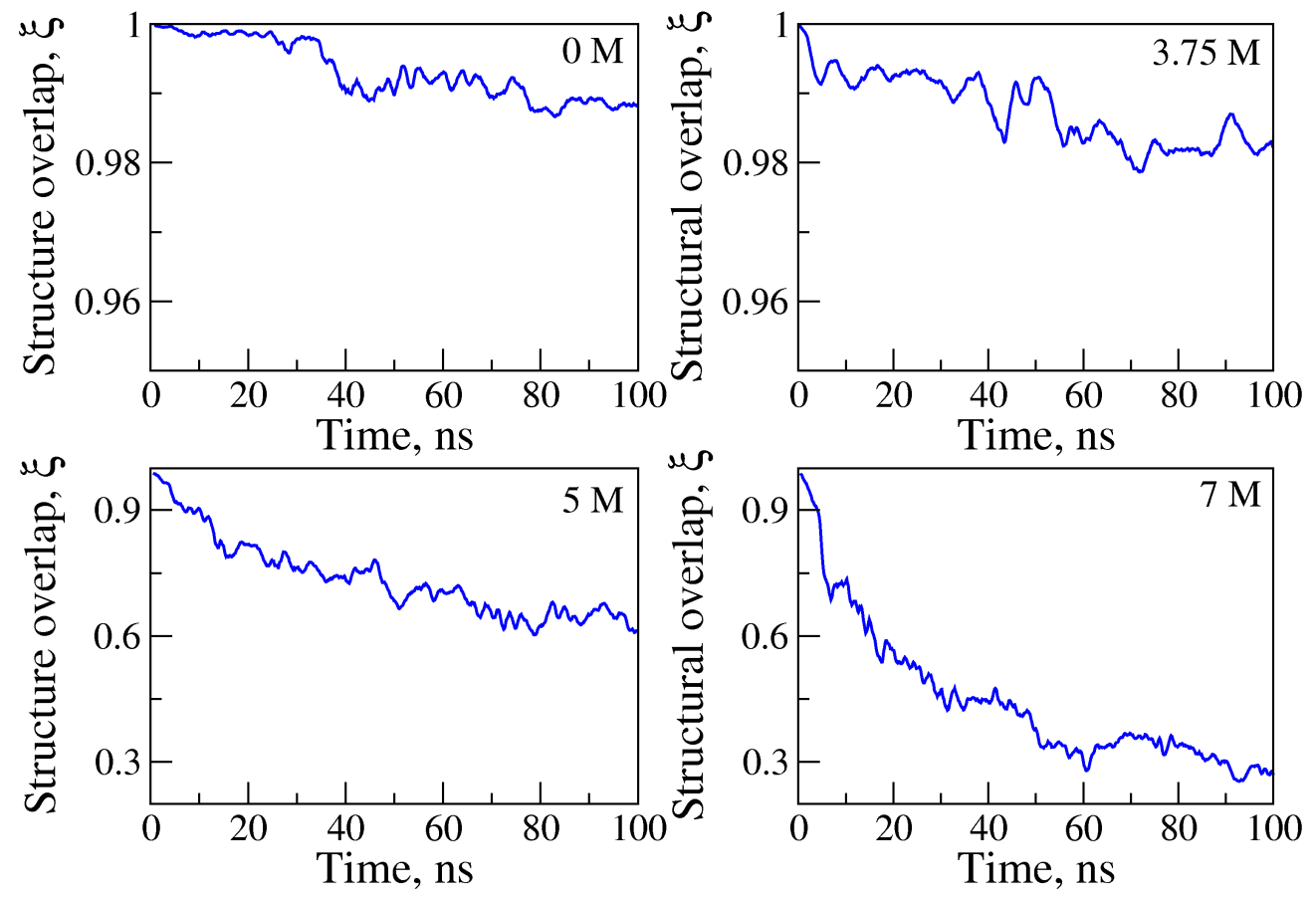

Figure S2. Tertiary structure dynamics of the BoNT/A in urea solution from MD simulations at $25^{\circ} \mathrm{C}$. Shown are the profiles of the structure overlap $\xi$ as a function of time (see Experimental Methods in main text).

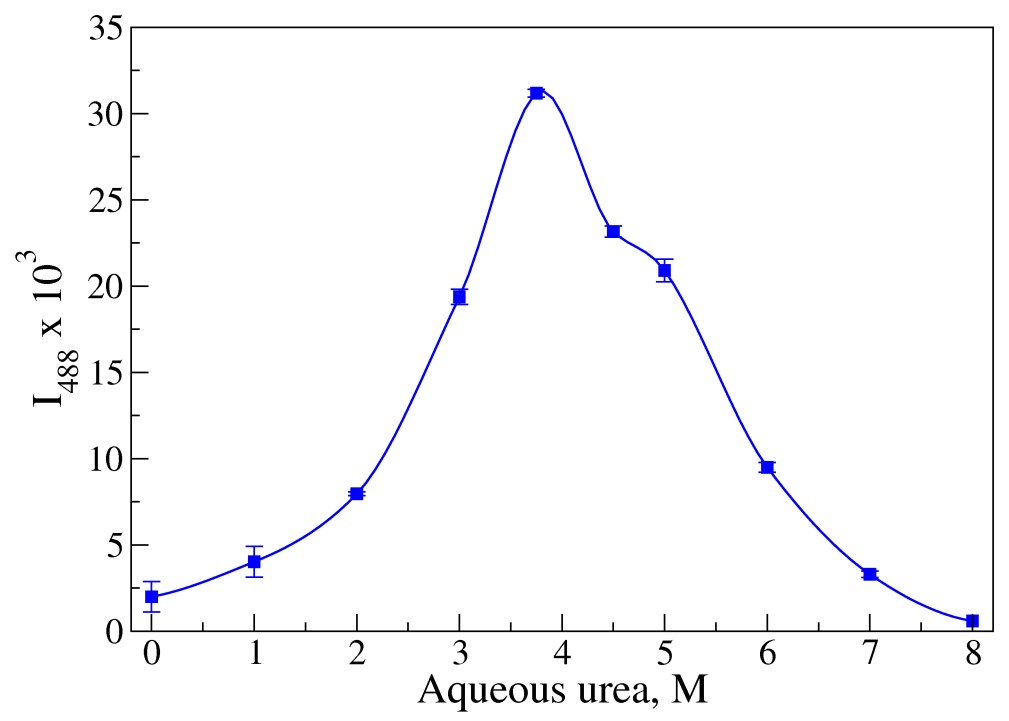

Figure S3. ANS (8-anilino-1-napthalene sulphonic acid) binding to urea denatured BoNT/A LC at room temperature $\left(25^{\circ} \mathrm{C}\right)$. Here, $I_{488}$ is the measured fluorescence emission intensity of ANS at $\lambda=488 \mathrm{~nm}$ after exciting the solution at $\lambda=388 \mathrm{~nm}$. ANS is a dye which binds to hydrophobic residues of a protein molecule. In this experiment, $70 \mu \mathrm{M}$ of ANS was titrated into $1 \mathrm{ml}$ of $1 \mu \mathrm{M}$ solution of BoNT/A LC dissolved in $10 \mathrm{mM}$ sodium phosphate buffer $(\mathrm{pH}=7.4)$, containing $50 \mathrm{mM} \mathrm{NaCl}, 1 \mathrm{mM}$ DTT, and urea at the required concentration in a $1 \mathrm{~cm}$ pathlength cuvette. 


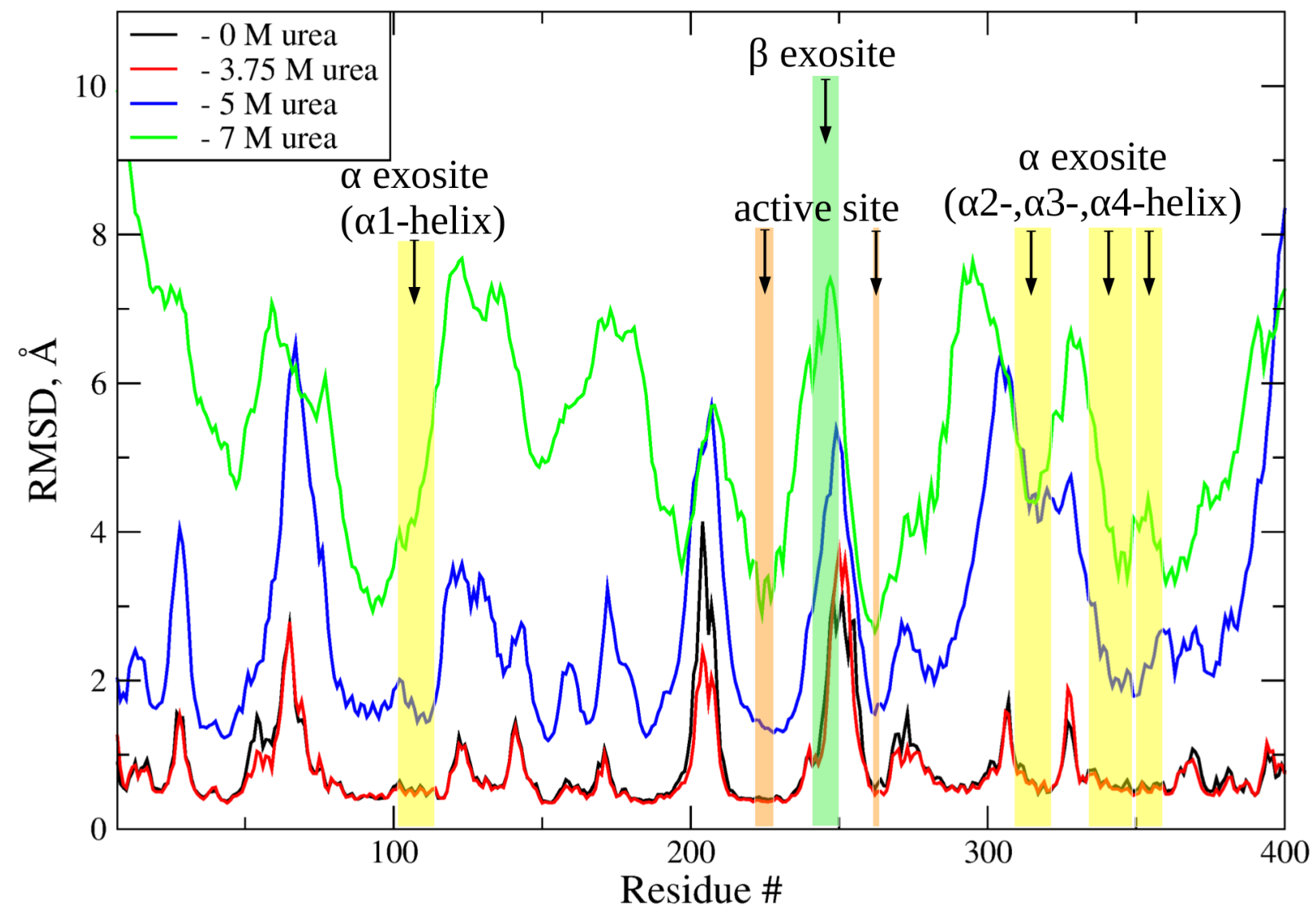

Figure S4. Equilibrium fluctuations of amino acid residues forming BoNT/A in 0 M, 3.75 M, 5 $\mathrm{M}$, and $7 \mathrm{M}$ urea solution at room temperature $\left(\mathrm{T}=25^{\circ} \mathrm{C}\right)$. Shown are the profiles of the rootmean-square-deviations (RMSD values) for residues $10-400$ of BoNT/A LC. Colored strips represent amino acids in the $\alpha$-exosite (shown in yellow), $\beta$-exosite (shown in green), and in the active site (shown in brown). We used same color denotation as in Figure 1 in the main text.

Table S1. Model systems for the BoNT/A light chain in urea solution in terms of ambient conditions (concentration of urea, $\mathrm{pH}$ and temperature), system size (number of amino acid residues in proteins, number of counterions, number of urea molecules, and number of water molecules), dimensions of the solvation box, the total length of a simulation run, and the CPU time expended.

\begin{tabular}{|c|c|c|c|c|c|c|c|}
\hline $\begin{array}{c}{[\text { Urea] }} \\
\mathrm{M}\end{array}$ & $\begin{array}{c}\mathrm{pH} ; \\
\mathrm{T},{ }^{\circ} \mathrm{C}\end{array}$ & $\begin{array}{c}\text { No.of counter- } \\
\text { ions Na}^{+} / \mathrm{Cl}^{-}\end{array}$ & $\begin{array}{c}\text { No.of urea } \\
\text { molecules }\end{array}$ & $\begin{array}{c}\text { No.of water } \\
\text { molecules }\end{array}$ & $\begin{array}{c}\text { Solvation box } \\
\left(\mathrm{x}_{2} \mathrm{y}_{\mathbf{2}} \mathrm{z}\right)\end{array}$ & $\begin{array}{c}\text { Length of } \\
\text { trajectory, ns }\end{array}$ & $\begin{array}{c}\text { CPU time, } \\
\text { hours }\end{array}$ \\
\hline 0 & $7 ; 25$ & $10 / 9$ & 0 & 20,407 & $90 \AA, 90 \AA, 90 \AA$ & 100 & $\sim 2,640$ \\
\hline 3.8 & $7 ; 25$ & $8 / 7$ & 1,707 & 13,958 & $90 \AA, 90 \AA, 90 \AA$ & 100 & $\sim 2,640$ \\
\hline 5 & $7 ; 25$ & $7 / 6$ & 2,864 & 15,235 & $90 \AA, 90 \AA, 90 \AA$ & 100 & $\sim 2,640$ \\
\hline 7 & $7 ; 25$ & $6 / 5$ & 2,764 & 10,841 & $90 \AA, 90 \AA, 90 \AA$ & 100 & $\sim 2,640$ \\
\hline
\end{tabular}

